\title{
Supranutritional selenium increases mammary gland vascularity in postpartum ewe lambs ${ }^{1}$
}

\author{
K. A. Vonnahme, ${ }^{2}$ C. M. Wienhold, P. P. Borowicz, T. L. Neville, D. A. Redmer, L. P. Reynolds, and J. S. Caton \\ Center for Nutrition and Pregnancy, Department of Animal Sciences, North Dakota State University, Fargo 58108
}

\begin{abstract}
Objectives were to determine the effects of maternal dietary supranutritional Se and nutritional plane during gestation on capillary surface density, capillary area density, and angiogenic factor expression in the developing mammary gland of primiparous ewes. Selenium treatments were initiated at breeding [adequate Se (ASe; $9.5 \mu \mathrm{g} / \mathrm{kg}$ of body weight) vs. high Se (HSe; 81.8 $\mu \mathrm{g} / \mathrm{kg}$ of body weight)] and nutritional planes at $\mathrm{d} 50$ of gestation [Low, 60\%; moderate (Mod), 100\%; and High, $140 \%$ of requirements). Mammary glands were collected within $24 \mathrm{~h}$ postpartum. Vascular development was assessed in the glandular portion of the mammary gland. Vascularity was determined for mammary tissue with the following measurements taken: the cross-sectional capillary area density (total capillary area as a proportion of tissue area) and capillary surface density (CSD; total capillary circumference per unit of tissue area). High-Se ewes had greater capillary surface and area densities compared with ASe ewes. A tendency existed for an Se $\times$ plane of nutrition interaction for CSD with maternal diet not affecting CSD in HSe ewes, but Low ewes had a decreased CSD compared with Mod ewes, with High being intermediate in ASe ewes. Moreover, HSe-Low and HSe-High ewes had increased CSD compared with ASe-Low and ASe-High, respectively. Although Se status did not influence angiogenic factor mRNA expression, mammary glands from Low ewes tended to have increased VEGF and FLT1 mRNA expression compared with High ewes, with Mod being intermediate. Maternal plane of nutrition did not affect mammary gland glutathione peroxidase activity, but it was increased in HSe compared with ASe ewes. Increased mammary capillary nutrient exchange area
\end{abstract}

Received September 16, 2010.

Accepted February 23, 2011.

${ }^{1}$ This project was partially supported by National Research Initiative Competitive Grants no. 2005-35206-15281 from the USDA Cooperative State Research, Education and Extension Service to J. S. Caton, D. A. Redmer, and K. A. Vonnahme; and by the Ronald E. McNair Post-Baccalaureate Achievement Program to C. M. Wienhold.

${ }^{2}$ Corresponding author: Kim.Vonnahme@ndsu.edu may contribute to previously observed changes in colostrum quality.

Key words: mammary gland, maternal nutrition intake, selenium, vascularity

\section{INTRODUCTION}

The quality and quantity of milk and colostrum is directly affected by maternal nutrition (Miranda et al., 1983; Swanson et al., 2008). In ewes, $98 \%$ of the mammary gland growth occurs during pregnancy, where the differentiation of the alveolar epithelial cells increases during the later stages of pregnancy (Anderson, 1975). Recently, our laboratory has shown that maternal nutrition from mid to late pregnancy influences colostrum yield and colostrum components (Swanson et al., 2008; Meyer et al., 2011), as well as the alveolar area that is capable of milk production later in lactation (Swanson et al., 2008). More recently, we have reported that when ewes are restricted to $60 \%$ of control intake during mid to late gestation, they produce less milk, even if fed similar diets postpartum (Meyer et al., 2011). Moreover, we have demonstrated that when ewes are supplemented high levels of Se from conception through term, they have greater milk production than ewes fed adequate levels of Se (Meyer et al., 2011). Selenium status of lactating dairy cows is an important regulator of mammary selenoprotein activity, namely glutathione peroxidase activity (Bruzelius et al., 2007), which may reduce cellular reactive oxygen species, and overall mammary gland health.

Mammary gland blood flow regulates the substrate supply for milk synthesis (Davis and Collier, 1985). More specifically, restriction of substrate supply to the mammary gland can alter the function and metabolic activity of mammary gland secretory cells (Davis and Collier, 1985). The mammary capillary network is essential for delivering the substrates needed for milk synthesis. Currently, limited data exists regarding effects of maternal nutrition on the development of the mammary gland capillary network. Based on our milk production data (Meyer et al., 2011), we hypothesize that supranutritional Se would increase, and nutrient restriction, but not excess, would decrease vascular- 
ity of the mammary gland. We further hypothesize that the changes in vascularity will be correlated with angiogenic factor mRNA expression in the mammary gland. Our specific objectives were to determine how supranutritional Se from breeding until term, and plane of nutrition from mid to late gestation affect the capillary development, angiogenic factor expression, and glutathione peroxide activity of the mammary gland immediately after parturition.

\section{MATERIALS AND METHODS}

\section{Animals and Diets}

Animal care and use was approved by the Institutional Animal Care and Use Committees at North Dakota State University (NDSU), Fargo, and the USDA-ARS, US Sheep Experiment Station (USSES), Dubois, ID. A full description of the breeding and feeding programs has been previously published (Swanson et al., 2008). Briefly, 160 Rambouillet ewe lambs (age $=240 \pm 17$ d) at the USSES were randomly assigned to Se treatment initiated at breeding. Selenium treatments were adequate $\mathrm{Se}$ (ASe; $9.5 \mu \mathrm{g} / \mathrm{kg}$ of BW) vs. high Se (HSe; $81.8 \mu \mathrm{g} / \mathrm{kg}$ of BW from Se-enriched yeast, Diamond V Mills, Inc., Cedar Rapids, IA) and were delivered in pellet form as a daily top dressing (100 g/ewe). Several research projects have been conducted in our laboratory using similar supranutritional levels Se with no signs of toxicity (Lawler et. al., 2004; Reed et al., 2007; Neville et al., 2008; Swanson et al., 2008; Carlson et al., 2009). During breeding through pregnancy diagnosis ( $\sim 33 \mathrm{~d}$ post-breeding) ewes were group fed (4 pens/Se treatment; 20 ewes/pen; $2.04 \mathrm{~kg} /$ ewe daily) a diet consisting of $47 \%$ alfalfa hay, $20 \%$ corn, $20 \%$ sugar beet pulp pellets, $8 \%$ malt barley straw, and 5\% concentrated separator byproduct (DM basis; Swanson et al., 2008). On approximately d 35 of gestation, 82 pregnant ewes were identified and shipped $(1,544 \mathrm{~km}$; $\sim 14 \mathrm{~h}$ ) to the Animal Nutrition and Physiology Center (ANPC) at NDSU for the remainder of the experiment. Ultimately, 40 and 42 ewes remained in the ASe and HSe treatments groups, respectively.

Upon arrival at NDSU, ewes remained on their assigned Se treatments. Ewes were individually housed in $0.91 \times 1.2 \mathrm{~m}$ pens in a temperature-controlled $\left(12^{\circ} \mathrm{C}\right)$ and ventilated facility for the duration of the study. Lighting within the facility was automatically timed to mimic daylight patterns. On d 50 of gestation, ewes (52.1 $\pm 0.9 \mathrm{~kg}$ ) were assigned randomly to 1 of 3 nutritional diets: $60 \%$ (Low), 100\% (moderate, Mod), or $140 \%$ (High) of the NRC (1985) requirements, resulting in a randomized design with a $2 \times 3$ factorial arrangement of treatments [ASe-Low $(\mathrm{n}=14)$; ASe-Mod $(\mathrm{n}=13)$;
ASe-High ( $\mathrm{n}=13)$; HSe-Low $(\mathrm{n}=14)$; HSe-Mod ( $\mathrm{n}=$ $14)$; HSe-High $(\mathrm{n}=14)]$. All diets were fed once daily in a complete pelleted form consisting of $36.5 \%$ beet pulp, $22.3 \%$ alfalfa meal, $16.2 \%$ ground corn, $18.0 \%$ soybean hulls, and 5 to $7 \%$ soybean meal $(0.48-\mathrm{cm}$ diameter; Swanson et al., 2008). The soybean meal was decreased to $5 \%$ in the high-Se pellet to accommodate the addition of $2 \%$ Se-enriched yeast (Diamond V Mills Inc.; Swanson et al., 2008). Ewes had free access to water and a trace mineralized salt block [containing no added Se; maximum $\mathrm{NaCl}$ (99\%), minimum $\mathrm{NaCl}(96 \%)$, and verified minimum amounts of $\mathrm{Mn}(2,000 \mathrm{mg} / \mathrm{kg}), \mathrm{Fe}$ $(1,000 \mathrm{mg} / \mathrm{kg}), \mathrm{Mg}(1,000 \mathrm{mg} / \mathrm{kg}), \mathrm{S}(500 \mathrm{mg} / \mathrm{kg}), \mathrm{Cu}$ $(250 \mathrm{mg} / \mathrm{kg})$, Co $(100 \mathrm{mg} / \mathrm{kg}), \mathrm{Zn}(80 \mathrm{mg} / \mathrm{kg})$, and I (70 mg/kg); Roto Salt Company, Penn Yan, NY]. Like diets fed at USSES, those fed at NDSU were formulated to be similar in ME and MP and to meet or exceed other nutrient requirements (NRC 1985; Swanson et al., 2008). Nutritional plane for the Low and High treatments was achieved by proportional downward (Low) or upward (High) shifts in dietary intake, resulting in global shifts in total nutrients supplied. Individual daily allotments of diets were usually totally consumed, with the appearance of orts being rare. Targeted ME requirements for Mod-fed animals were based on NRC (1985) recommendations for $60-\mathrm{kg}$ BW, pregnant ewe lambs during mid- to late gestation (ADG of $140 \mathrm{~g} / \mathrm{d}$ ), and adjusted to $2.36 \mathrm{Mcal}$ of $\mathrm{ME} / \mathrm{d}$, based on previous experience for this type of ewe consuming similar diets and being housed in the ANPC unit at NDSU. The supply of ME needed per ewe was then adjusted by and adding or subtracting $0.0198 \mathrm{Mcal}$ of ME per $\mathrm{kg}$ of BW above or below the initial 60-kg BW target. Daily DMI for individual ewes of the respective diets were then determined based upon ME demand and dietary ME composition (Swanson et al., 2008). As the adequate and high Se pelleted diets were similar in ME (2.63 and $2.64 \mathrm{Mcal}$ of $\mathrm{ME} / \mathrm{kg}$, respectively), Se targets for HSe treatments were met by blending the adequate and high Se pellets. Body weight was measured every $14 \mathrm{~d}$, and the diets were adjusted accordingly.

\section{Slaughter Procedures and Mammary Gland Processing}

Ewes were slaughtered between 3 and $22 \mathrm{~h}$ after parturition. Just before slaughter, each ewe was weighed to obtain a final BW. One milliliter of oxytocin (20 IU; AgriLabs, St. Joseph, MO) was delivered to facilitate milk let-down and milk was manually collected immediately before slaughter to obtain an empty mammary gland weight. Ewes were stunned by captive bolt (Supercash Mark 2, Acceles and Shelvoke Ltd., Birmingham, UK), exsanguinated, and maternal 
tissues harvested. The digesta was stripped from the gastrointestinal tract. The entire mammary gland was dissected from the skin, weighed, and immediately processed.

From one-half of the gland, 5 samples (approximately 1-g each) of glandular tissue from the mammary gland were snap frozen in super-cooled isopentane (submerged in liquid nitrogen) and stored at $-80^{\circ} \mathrm{C}$ until analysis for mRNA expression (Neville et al., 2010). The remaining half of the mammary gland was immediately perfusion fixed with Carnoy's fixative $(70 \%$ ethanol, $30 \%$ acetic acid, $10 \%$ chloroform) by cannulating the cranial mammary artery with a polyethylene $(\mathrm{PE}-60 ;$ o.d. $=1.22 \mathrm{~mm}$; i.d. $=0.77 \mathrm{~mm}$; Intramedic Becton Dickinson and Company, Sparks, MD) beveled catheter that was secured to surrounding tissue. The mammary gland was initially perfused with PBS, then with Evan's blue dye (to define the vasculature), then with PBS again, and then, finally, was perfusion fixed with Carnoy's fixative. Mammary tissue was then cut into approximately 1-cm cubes and was further immersion fixed in Carnoy's fixative for an additional $24 \mathrm{~h}$. Thereafter, mammary gland tissues were dehydrated in a series of ethanol, Histo-Clear (National Diagnostics, Atlanta, GA), and embedded in paraffin wax.

\section{Histochemistry and Capillary Vascularity Assessment}

The perfused mammary gland tissue blocks were sectioned at $4 \mu \mathrm{m}$ and mounted on glass slides. Immunohistochemistry was performed using an antibody to Factor VIII, a specific endothelial cell marker, as described previously by our laboratory (Grazul-Bilska et al., 2010) and counter-stained by using periodic acidSchiff staining procedures to provide contrast to the vascular tissue, as described previously (Borowicz et al., 2007; Vonnahme et al., 2007). Photomicrographs were taken at $400 \times$ magnification using a Nikon Eclipse E800 microscope equipped with a Nikon DXM 1200F digital camera $\left(\mathrm{n}=10\right.$ pictures per slide, $85,734.7 \mu \mathrm{m}^{2}$ per picture; Nikon, Inc., Melville, NY). Vascularity was then determined by image analysis (Image-Pro Plus, version 5.0; Media Cybernetics, Houston, TX; Borowicz et al., 2007; Vonnahme et al., 2007). Briefly, for each ewe, 10 areas per mammary gland (in the alveolar area; Figure 1) were analyzed for tissue area, shrinkage area (i.e., the effect of fixation) and luminal area (which were both subtracted from the tissue area), cross-sectional capillary area density (total capillary area as a proportion of tissue area), and capillary surface density (CSD, total capillary circumference per unit of tissue area), which is proportional to capillary surface area (Borowicz et al., 2007; Vonnahme et al., 2007).

\section{Glutathione Peroxidase Analysis}

Mammary gland samples were analyzed for Se-dependent glutathione peroxidase (GPx) activity according to the procedures reported by Paglia and Valentine (1967) and as previously reported by our laboratory (Lekatz et al., 2010). Briefly, homogenized sample, 0.12 $M$ phosphate buffer, and a reaction mixture [NADPH (N-6505; Sigma Diagnostic, St. Louis, MO), reduced glutathione (G-4251; Sigma Diagnostic), glutathione reductase (G-4751; Sigma Diagnostic), and phosphate buffer $(0.12 M)$ ] were added to each well in triplicate. Three wells were filled with $35 \mu \mathrm{L}$ of buffer solution only as a blank. Thirty-three microliters of hydrogen peroxide $(16.5 \%)$ were added to each well. Three plates (96 Microwell plates, 260844; Nunc Intl., Rochester, NY) were used, and absorbance was read at $340 \mathrm{~nm}$ (Spectra Max 340, Fullerton, CA) for 4 min at 15-s intervals to measure the oxidation of NADPH to NADP. Using the protein concentration for each sample, the specific activity of GPx was calculated. The intraassay and interassay CV averaged 5.6 and $8.6 \%$, respectively.

\section{Quantitative Reverse-Transcriptase PCR Analysis}

Maternal mammary gland mRNA was analyzed for expression of angiogenic factors and their receptors (Table 1), including vascular endothelial growth factor ( $\boldsymbol{V E G F}$ ), fms-related tyrosine kinase 1 (FLT1), kinase insert domain receptor $(\boldsymbol{K D} \boldsymbol{R})$, endothelial nitric oxide synthase 3 (NOS3), and the receptor for NOS3, soluble guanylate cyclase ( $\boldsymbol{G} \boldsymbol{U} \boldsymbol{C} \boldsymbol{Y} \mathbf{1 B} 3)$. Methods used for extraction and quantification of mRNA and the analysis of major angiogenic factors and their TaqMan probe and primer sequences have been published (Redmer et al., 2005; Johnson et al., 2006; Vonnahme et al., 2006; Neville et al., 2010). Analyses were conducted using TaqMan reagents and procedures purchased from and recommended by Applied Biosystems (Foster City, $\mathrm{CA})$.

Expression of each angiogenic factor was normalized to expression of $18 \mathrm{~S}$ in a multiplex reaction using the human $18 \mathrm{~S}$ pre-developed assay reagent (PDAR) from Applied Biosystems. The PDAR solution, which is primer limited and contains a VIC-labeled probe (a proprietary reporter dye; Applied Biosystems), was further adjusted by using one-fourth the normal amount, so that it would not interfere with amplification of the FAM (6-carboxy-fluorescein)-labeled gene of interest. The multiplex reaction was also used to prepare standard curves for $18 \mathrm{~S}$ and the gene of interest based on dilutions of cDNA obtained from reverse transcription of RNA obtained from pooled late-pregnancy sheep placentomal tissues. 
Table 1. The genes of interest and the proposed function of each angiogenic gene ${ }^{1}$

\begin{tabular}{ll}
\hline Gene of interest & Proposed function \\
\hline Vascular endothelial growth factor $($ VEGF) & Potent angiogenic factor; causes endothelial proliferation and migration, \\
fms-related tyrosine kinase $1(F L T 1)$ & acts via KDR and FLT1 receptors \\
Kinase insert domain receptor $(K D R)$ & Receptor for VEGF \\
Endothelial nitric oxide synthase $3(N O S 3)$ & Receptor for VEGF \\
Soluble guanylate cyclase $(G U C Y 1 B 3)$ & Aids in nitric oxide production, vasodilator \\
\hline
\end{tabular}

${ }^{1}$ Adapted from Vonnahme et al. (2006).

\section{Dietary Analysis}

Diet samples were analyzed for DM, ash, N, (Methods 930.15, 942.05, and 990.02, respectively; AOAC, 1990), ADF, and NDF (Ankom, Fairport, NY) contents. Diet, colostrum, and plasma samples were prepared for Se analysis and have been previously reported (Swanson et al., 2008). Hydride generation atomic absorption spectroscopy (5100 AAS; Perkin-Elmer Inc., Boston, MA) was used for Se analysis, as previously reported (Finley et al., 1996).

\section{Statistical Analyses}

Of the original 82 ewes in the study, 6 ewes gave birth to twins, and their tissues were not analyzed for any measures in this study. Thus, the number of ewes per treatment was as follows: ASe-Low $(\mathrm{n}=14)$; ASe-Mod $(\mathrm{n}=12)$; ASe-High $(\mathrm{n}=13)$; HSe-Low $(\mathrm{n}=$ 11); HSe-Mod ( $=13)$; HSe-High ( $\mathrm{n}=13)$. Data were analyzed as a completely randomized design with a 2 $\times 3$ factorial arrangement of treatments using ANOVA (PROC GLM; SAS Inst. Inc., Cary, NC). The model

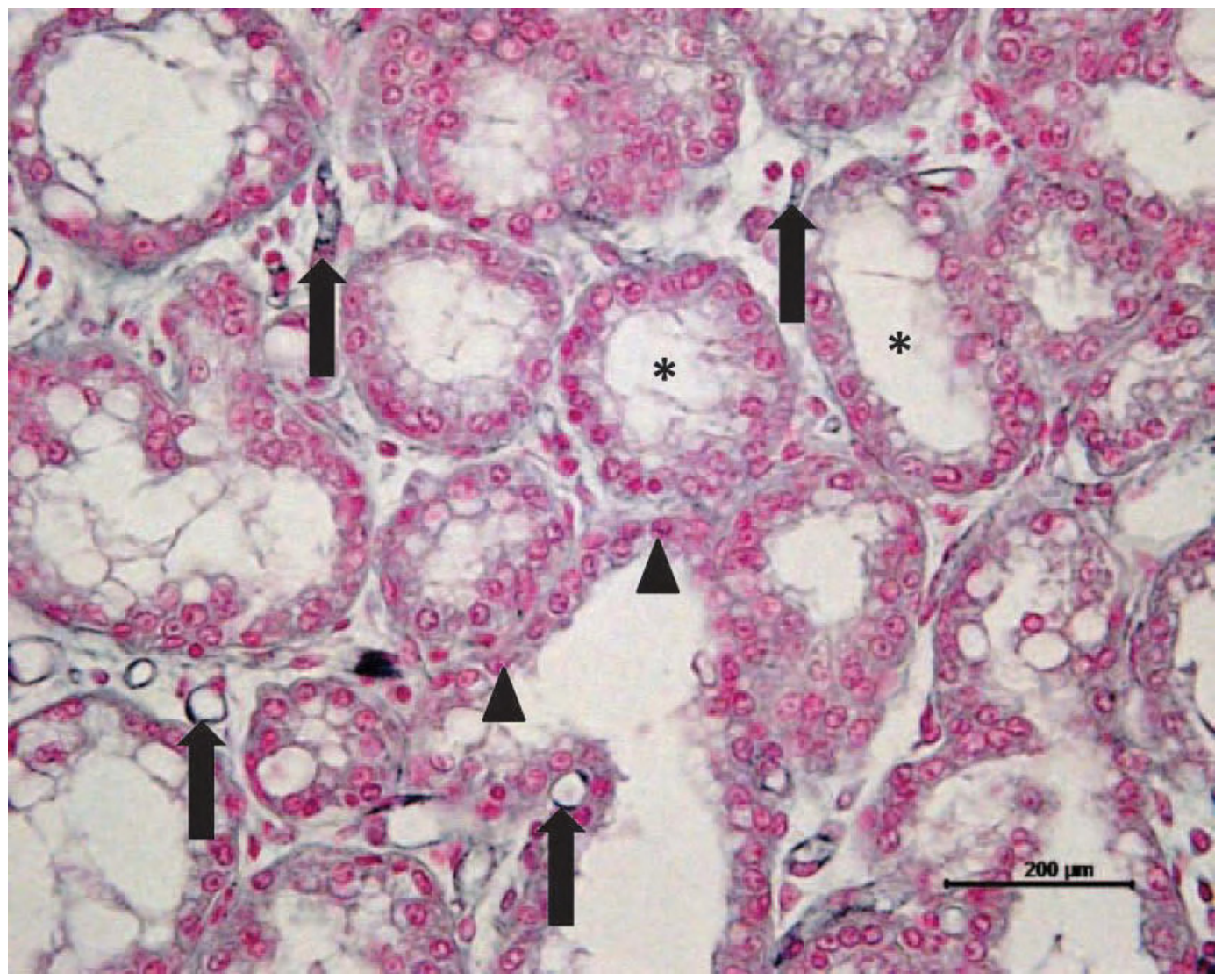

Figure 1. Representative image of a cross section of the ovine mammary gland used in the current study. Arrows indicate positive Factor VIII (a specific endothelial cell marker) staining and denoted capillaries. Arrowheads indicate alveolar epithelial cells. *Indicates alveolar lumen area. Color version available in the online PDF. 


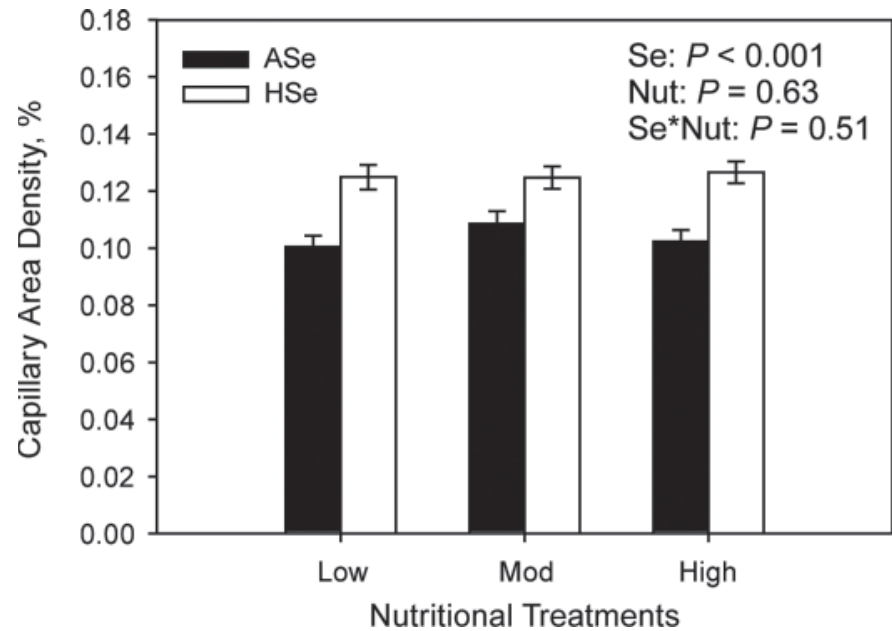

Figure 2. Effects of supranutritional Se and maternal plane of nutrition (Nut) intake on mammary gland capillary area density. ASe $=$ adequate Se; HSe $=$ high Se; Low $=60 \%$ of NRC recommendations; Mod $=100 \%$ of NRC recommendations; High $=140 \%$ of NRC recommendations.

contained the level of Se (ASe vs. HSe), plane of nutrition (Low, Mod, High), and the Se $\times$ plane of nutrition interaction. When interactions were present $(P<0.10)$, means were separated by the least significant difference test. To understand the relationships between the angiogenic factor mRNA expression and the vascularity measurements, correlations were performed using PROC CORR (SAS Inst. Inc., Cary, NC). Correlations were determined within each dietary group (i.e., ASeLow, ASe-Mod, among the others), as well as across Se treatments and nutritional plane treatments.

\section{RESULTS}

Mammary gland and ewe weights have been presented previously (Swanson et al., 2008). Briefly, Se status did not alter ewe weight $(58.6 \pm 0.9 \mathrm{~kg})$, or the weight of the mammary glands. Ewes increased in BW with increased maternal plane of nutrition (i.e., 48.1, $58.5,69.1 \pm 1.1 \mathrm{~kg}$ for Low, Mod, and High ewes, respectively; Swanson et al., 2008). Whereas mammary gland weight was similar between Mod and High ewes, Low ewes had smaller gland weight. However, when expressed per BW, the mammary gland weight was decreased in the High ewes, with Low and Mod ewes being similar (Swanson et al., 2008).

No effect $(P \geq 0.51)$ of maternal plane of nutrition on capillary area density or interaction with plane of nutrition and Se level was observed. Capillary area density was increased $(P<0.001)$ in mammary glands from HSe ewes compared with ASe ewes $(0.125 \pm 0.002 \%$ vs. $0.104 \pm 0.002 \%$; Figure 2). No main effect of maternal plane of nutrition $(P=0.53)$ on CSD was found. A main effect of Se status was observed, with HSe ewes having mammary glands with greater capillary CSD than those of ASe ewes $(90.69 \pm 2.44$ vs. $72.46 \pm 2.51$ $\mu \mathrm{m})$. However, a tendency existed for a Se $\times$ plane of nutrition interaction $(P=0.07$; Figure 3$)$. Although maternal plane of nutrition did not alter $(P \geq 0.18)$ CSD in the HSe ewes, ASe-Low ewes had decreased ( $P$ $=0.05$ ) mammary CSD compared with ASe-Mod ewes, with ASe-High being intermediate. Moreover, HSe-Low and HSe-High ewes had mammary glands with greater $(P<0.01)$ CSD compared with ASe-Low and ASeHigh ewes. No effect $(P=0.23)$ of Se status on Mod ewe mammary gland CSD was observed (Figure 3).

No effect was observed $(P>0.19)$ of maternal plane of nutrition, supranutritional Se, or their interaction on mRNA expression of $K D R, N O S 3$, and GUCY1B3 in mammary glands. A tendency existed $(P \leq 0.09)$ for Low ewes to have increased $(P \leq 0.05)$ amounts of $V E G F$ and FLT1 mRNA expression compared with High ewes with Mod being intermediate (Table 2). Maternal Se status did not affect $(P>0.39) V E G F$ or FLT1 mRNA expression.

When correlations were performed between the angiogenic factor mRNA expression and capillary measurements within a dietary treatment, only $K D R$ mRNA expression and CSD were of interest (Figure 4). Although no significant correlation between $K D R$ mRNA expression and CSD in HSe ewes was observed (Figure 4B), interesting relationships in the ASe ewes were observed (Figure 4A). Mammary gland $K D R$

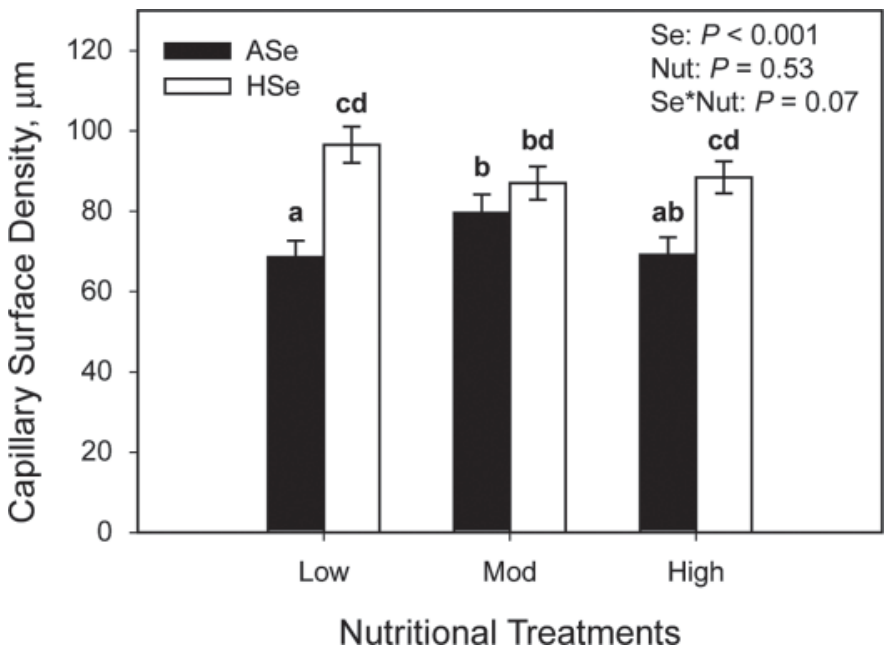

Figure 3. Effects of supranutritional Se and maternal plane of nutrition (Nut) on mammary gland capillary surface density. ASe $=$ adequate Se; $\mathrm{HSe}=$ high Se; Low $=60 \%$ of NRC recommendations; Mod $=100 \%$ of NRC recommendations; High $=140 \%$ of NRC recommendations. ${ }^{\text {a-d }}$ Least squares means \pm standard error of the means with different letters differ; $P \leq 0.01$. 
Table 2. Main effects of level of nutrition (Nut) and supranutritional Se on angiogenic factors measured in maternal mammary gland

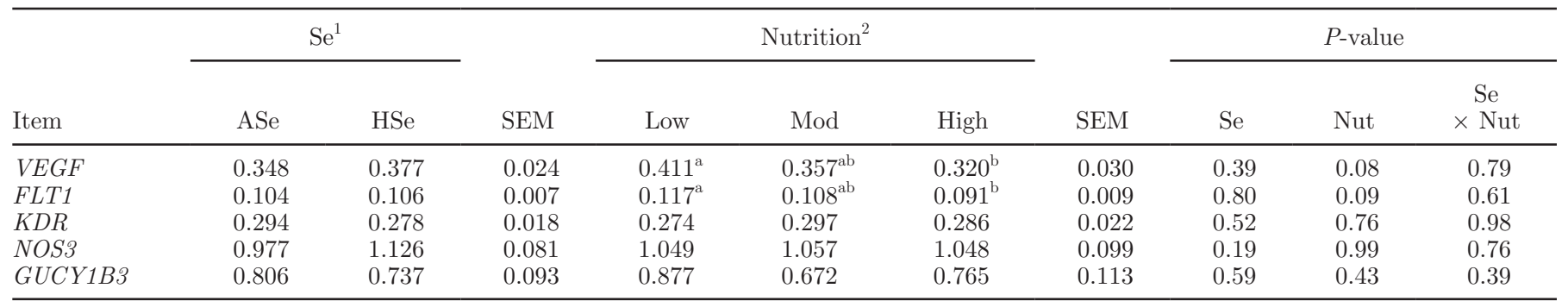

${ }^{\mathrm{a}, \mathrm{b}} \mathrm{LSM} \pm \mathrm{SEM}$ within a row differ by unprotected LSD, $P<0.05$.

${ }^{1} \mathrm{Se}: 7.4 \mu \mathrm{g} / \mathrm{kg}$ of BW (ASe = no added Se) vs. $81.5 \mu \mathrm{g} / \mathrm{kg}$ of BW (HSe).

${ }^{2}$ Low $=$ ewes fed to $60 \%$ of Mod; Mod $=$ non-restricted ewes fed at requirements; High = ewes fed to $140 \%$ of Mod.

mRNA expression was negatively correlated $(P \leq 0.04)$ with CSD in ASe-Mod and ASe-High ewes, but not $(P=0.63)$ in ASe-Low ewes. When correlations were performed within Se treatments only, the $K D R$ mRNA expression remained negatively correlated $(\mathrm{r}=0.46 ; P$ $=0.01)$ to CSD in the ASe ewes, whereas no association in HSe ewes $(\mathrm{r}=-0.06 ; P=0.72)$ was present. When performing correlations within each nutritional plane, interesting observations between FLT1 and CSD, as well as $V E G F$ and CSD, were noted. In High ewes, both FLT1 (Figure 5) and VEGF (Figure 6) were positively correlated $(P \leq 0.01)$ with CSD, whereas Low and Mod ewes did not exhibit this relationship.

Maternal plane of nutrition did not affect $(P=0.83)$ GPx activity in the mammary gland. However, HSe ewes had increased $(P=0.003)$ mammary gland $\mathrm{GPx}$ activity compared with ASe ewes $(23.52 \pm 1.24$ vs. $17.94 \pm 1.28$ units/mg; Figure 7).

\section{DISCUSSION}

We have demonstrated that supranutritional Se and plane of nutrition affect the vascular development of the mammary gland. We accept our hypothesis that Se would increase vascular development of the mammary gland, but plane of nutrition did not affect the gland as much as we originally anticipated. Furthermore, as expected, GPx activity was greater in mammary glands that were from HSe ewes.

We have previously published (Neville et al., 2010) that mammary glands from ewes that were restricted to $60 \%$ of NRC requirements (similar to this study) had an increase in $V E G F$ mRNA expression. In this study, the Low and Mod ewes had similar VEGF mRNA expression, but $V E G F$ expression was greater in the Low ewes compared with the High. The increase in $V E G F$ mRNA expression may be due to an increased hypoxic environment, or it may be stimulated by the increased estradiol concentrations that Low ewes have compared with Mod and High (Camacho et al., 2010). Both hypoxia and estradiol can stimulate $V E G F$ production
(Cheung, 1997; Reynolds et al., 1998). The increased $V E G F$ and FLT1 in the mammary gland of Low ewes were not associated with mammary gland vascularity as they were in High ewes. In these same ewes, colostrum
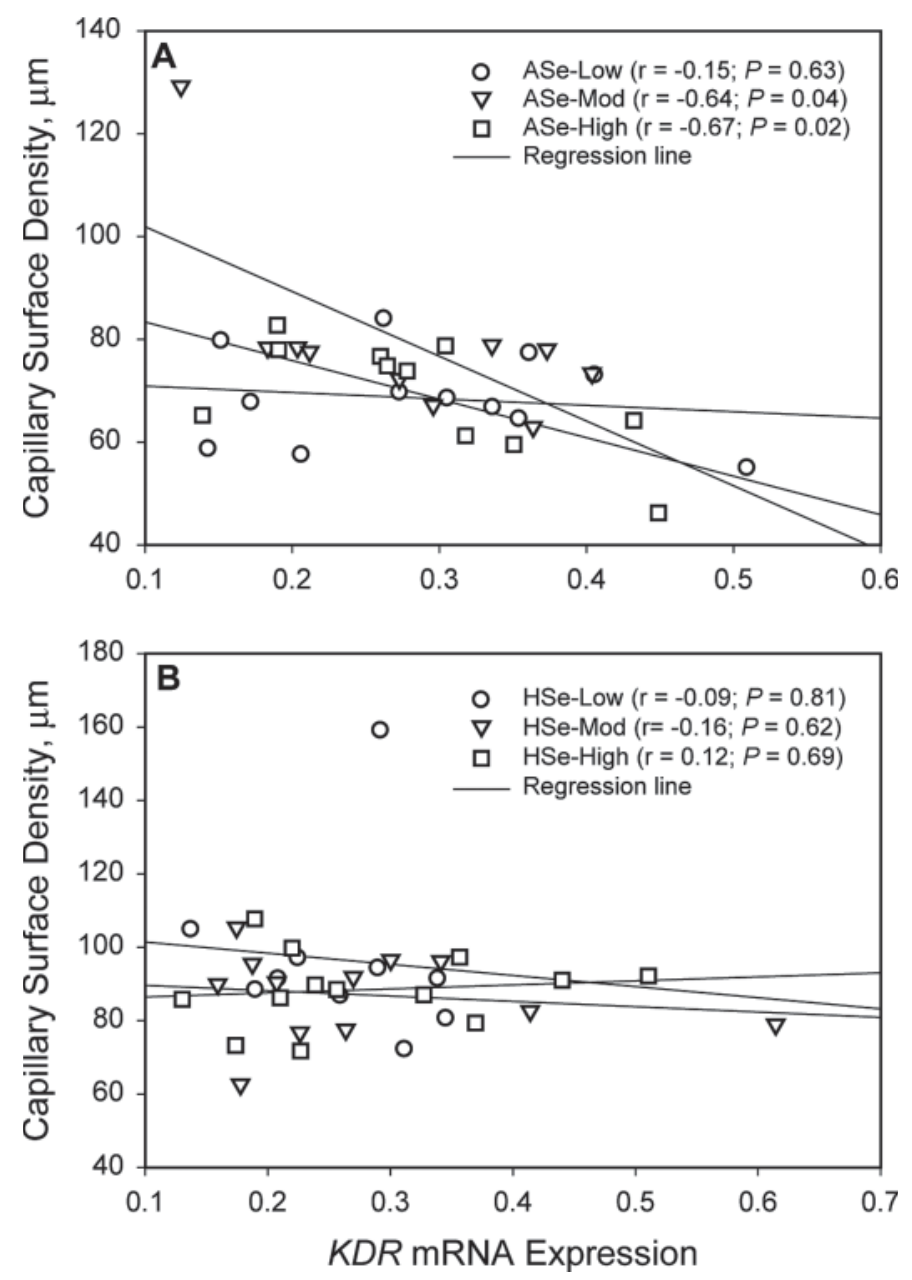

Figure 4. Correlations between kinase insert domain receptor $(K D R)$ mRNA expression and capillary surface density in the mammary gland of adequate-Se (ASe) ewes (A) and high-Se (HSe) ewes (B) across nutritional planes. Low $=60 \%$ of NRC recommendations; Mod $=100 \%$ of NRC recommendations; High $=140 \%$ of NRC recommendations. 


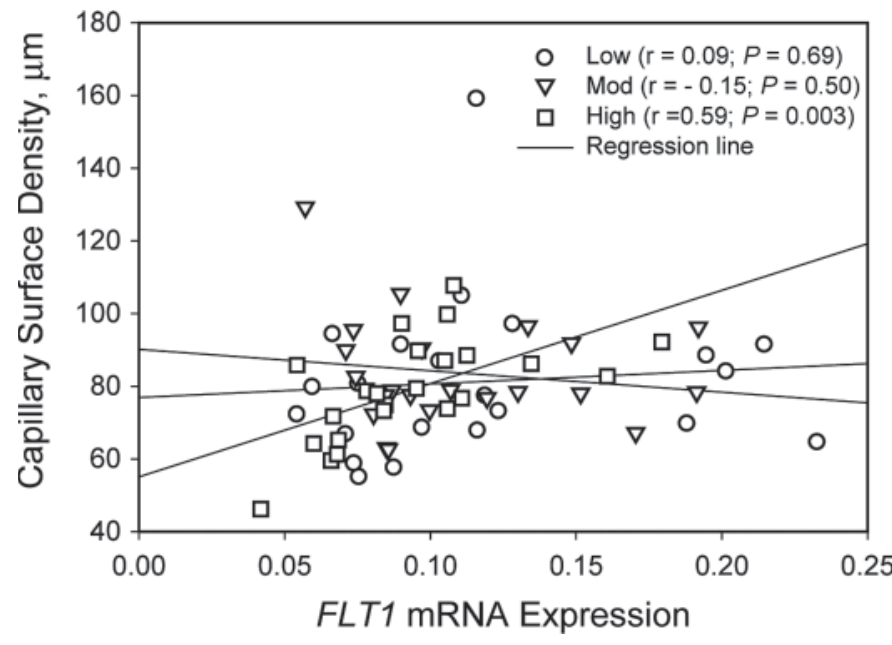

Figure 5. Correlations between fms-related tyrosine kinase 1 (FLT1) mRNA expression and capillary surface density in the mammary gland from Low (60\% of NRC recommendations), Mod (100\% of NRC recommendations), and High (140\% of NRC recommendations) ewes.

quantity was decreased in both Low and High ewes (Swanson et al., 2008). However, in a similar experiment, High ewes regained the ability to have a similar quantity and quality of milk as did Mod ewes, whereas Low ewes did not (Meyer et al., 2011). Perhaps vascular development of the gland in High ewes may be still adapting to the maternal nutrient status. On average, High ewes had a shorter gestation length than did Low and Mod ewes (Swanson et al., 2008), and therefore, development may have been slightly altered. Vascular

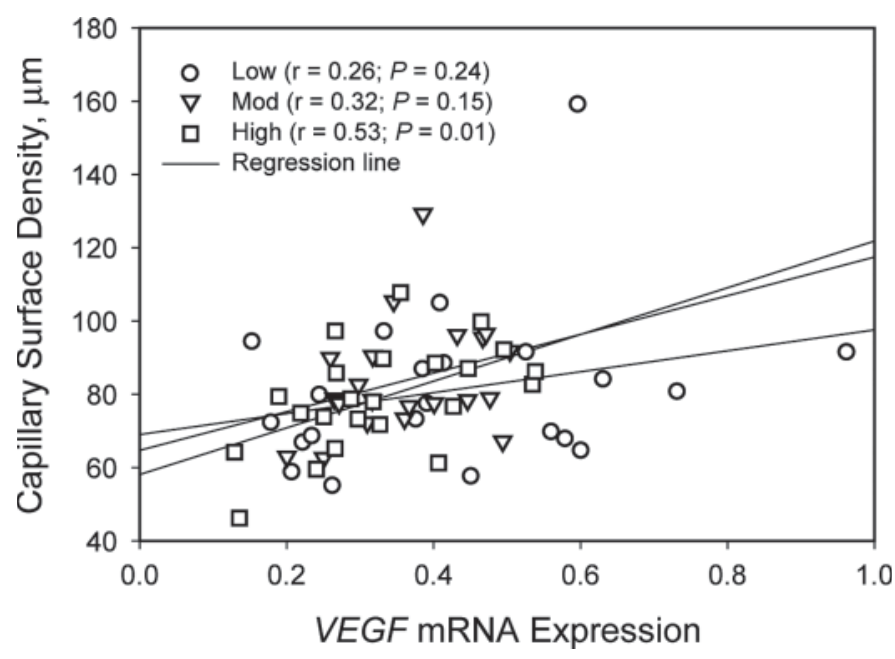

Figure 6. Correlations between vascular endothelial growth factor ( VEGF) mRNA expression and capillary surface density in the mammary gland from Low (60\% of NRC recommendations), Mod (100\% of NRC recommendations), and High (140\% of NRC recommendations) ewes.

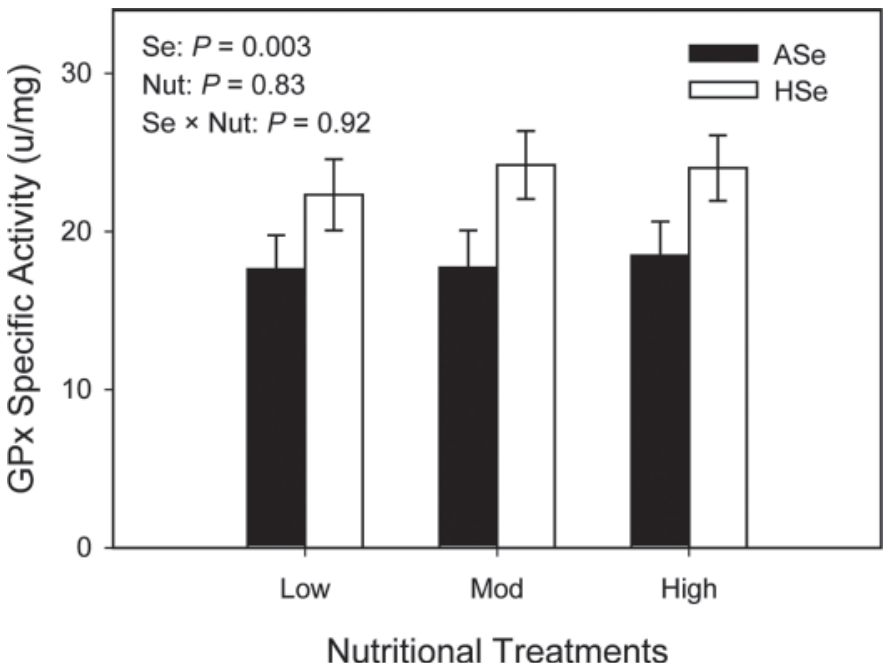

Figure 7. Effects of supranutritional Se and maternal plane of nutrition (Nut) on mammary gland glutathione peroxidase (GPx) activity. $\mathrm{ASe}=$ adequate $\mathrm{Se}$; HSe $=$ high $\mathrm{Se} ; \mathrm{Low}=60 \%$ of NRC recommendations; $\operatorname{Mod}=100 \%$ of NRC recommendations; High $=140 \%$ of NRC recommendations.

endothelial growth factor acting through FLT1 increases permeability of the vasculature (Vogel et al., 2007). Perhaps the different associations that were observed in the current study within the High ewes allow for vascular alterations to occur shortly after birth, allowing the quantity and quality of milk to reach normal levels (i.e., as compared with Mod ewes; Meyer et al., 2011). The role that $K D R$ may be playing in vascular development of the mammary gland is a bit perplexing. Within the ASe ewes, there was a negative correlation in Mod and High ewes between KDR mRNA expression and CSD, with no correlation observed in Low ewes. It has been reported that $V E G F$ acting through $K D R$ increases capillary tube formation (Koolwijk et al., 2001). Perhaps proliferation of capillaries has peaked by birth within the mammary gland. Nonetheless, the relationship between maternal nutrition and vascular development of the gland is of interest.

The interesting finding in the current study is the increase in mammary gland vascularity through supranutritional Se. Interestingly, when ewes are supplemented with Se at approximately 10 times above current recommendations throughout gestation, mammary gland vascularity was enhanced. We hypothesize the observed increase in capillary vascularity is a potential mechanism for the increased milk production we observed in HSe ewes compared with ASe ewes for a 20-d lactation period (Meyer et al., 2011). Lacetera et al. (1996) reported an increase in colostrum and milk production in dairy cows supplemented with sodium selenite $(5 \mathrm{mg} / 100 \mathrm{~kg}$ of BW). These authors also observed increased GPx activity in erythrocytes of Se-supplemented cows. Al- 
though erythrocyte GPx activity was used as a marker of Se status, it nonetheless parallels the current study where we observed increased GPx activity within the mammary gland tissue itself. Although the mechanisms for why supranutritional Se increases milk production still remain unknown, a combination of an environment with reduced reactive oxygen species in the mammary secretory cells, as well as an increased blood flow and nutrient exchange area may help augment the process of lactogenesis. Future studies are needed to determine how Se may enhance mammary gland health and milk production capabilities.

In summary, although maternal plane of nutrition affects the developing mammary gland, supranutritional Se may be a more potent factor that has the potential to drive milk production. Selenium status may influence the vascularity of the mammary gland, thus allowing for more nutrient availability for increased milk production. Moreover, the mechanisms for the observed decrease in milk production of restricted ewes compared with control-fed ewes (Meyer et al., 2011) are still unknown.

\section{REFERENCES}

Anderson, R. R. 1975. Mammary gland growth in sheep. J. Anim. Sci. $41: 118-123$.

AOAC. 1990. Official Methods of Analysis. Vol. I. 15th ed. Association of Official Analytical Chemists, Arlington, VA.

Borowicz, P. P., D. R. Arnold, M. L. Johnson, A. T. Grazul-Bilska, D. A. Redmer, and L. P. Reynolds. 2007. Placental growth throughout the last two thirds of pregnancy in sheep: Vascular development and angiogenic factor expression. Biol. Reprod. 76:259-267.

Bruzelius, K., T. Hoac, R. Sundler, G. Önning, and B. Åkesson. 2007. Occurrence of selenoprotein enzyme activities and mRNA in bovine mammary tissue. J. Dairy Sci. 90:918-927.

Camacho, L. E., A. M. Meyer, D. M. Hallford, G. Perry, L. P. Reynolds, J. S. Caton, and K. A. Vonnahme. 2010. Effects of nutritional plane and dietary selenium during gestation on serum prolactin and estradiol-17 $\beta$ (E2) in ewe lambs during pregnancy and lactation. J. Anim. Sci. 88(E-Suppl. 3):82.

Carlson, D. B., J. J. Reed, P. P. Borowicz, J. B. Taylor, L. P. Reynolds, T. L. Neville, D. A. Redmer, K. A. Vonnahme, and J. S. Caton. 2009. Effects of dietary selenium supply and timing of nutrient restriction during gestation on maternal growth and body composition of pregnant adolescent ewes. J. Anim. Sci. 87:669-680.

Cheung, C. Y. 1997. Vascular endothelial growth factor: Possible role in fetal development and placental function. J. Soc. Gynecol. Investig. 4:169-177.

Davis, S. R., and R. J. Collier. 1985. Mammary blood flow and regulation of substrate supply for milk synthesis. J. Dairy Sci. 68:10411058.

Finley, J. W., L. Matthys, T. Shuler, and E. Korynta. 1996. Selenium content of foods purchased in North Dakota. Nutr. Res. 16:723-728.

Grazul-Bilska, A. T., P. P. Borowicz, M. L. Johnson, M. A. Minten, J. J. Bilski, R. Wroblewski, D. A. Redmer, and L. P. Reynolds. 2010. Placental development during early pregnancy in sheep: Vascular growth and expression of angiogenic factors in maternal placenta. Reproduction 140:165-174.

Johnson, M. L., A. T. Grazul-Bilska, D. A. Redmer, and L. P. Reynolds. 2006. Effects of estradiol-173 on expression of mRNA for seven angiogenic factors and their receptors in the endometrium of ovariectomized (OVX) ewes. Endocrine 30:333-342.

Koolwijk, P., E. Peters, B. van der Vecht, C. Hornig, H. A. Weich, K. Alitalo, D. J. Hicklin, Y. Wu, L. Witte, and V. W. van Hinsbergh. 2001. Involvement of $V E G F R-2(k d r / f l k-1)$ but not VEGFR-1 (flt1) in $V E G F-A$ and $V E G F-C$-induced tube formation by human microvascular endothelial cells in fibrin matrices in vitro. Angiogenesis $4: 53-60$.

Lacetera, N., U. Bernabucci, B. Ronchi, and A. Nardone. 1996. Effects of selenium and vitamin $\mathrm{E}$ administration during a late stage of pregnancy on colostrum and milk production in dairy cows, and on passive immunity and growth of their offspring. Am. J. Vet. Res. 57:1776-1780.

Lawler, T. L., J. B. Taylor, J. W. Finley, and J. S. Caton. 2004. Effect of supranutritional and organically bound selenium on performance, carcass characteristics, and selenium distribution in finishing beef steers. J. Anim. Sci. 82:1488-1493.

Lekatz, L. A., J. S. Caton, J. B. Taylor, L. P. Reynolds, D. A. Redmer, and K. A. Vonnahme. 2010. Maternal selenium supplementation and timing of nutrient restriction in pregnant sheep: Impacts on maternal endocrine status and placental characteristics. J. Anim. Sci. 88:955-971.

Meyer, A. M., J. J. Reed, T. L. Neville, J. F. Thorson, K. R. MaddockCarlin, J. B. Taylor, L. P. Reynolds, D. A. Redmer, J. S. Luther, C. J. Hammer, K. A. Vonnahme, and J. S. Caton. 2011. Nutritional plane and selenium supply during gestation affect yield and nutrient composition of colostrum and milk in primiparous ewes. J. Anim. Sci. 89:1627-1639. doi:10.2527/jas.2010-3394.

Miranda, R., N. G. Saravia, R. Ackerman, N. Murphy, S. Berman, and D. N. McMurray. 1983. Effect of maternal nutritional status on immunological substances in human colostrum and milk. Am. J. Clin. Nutr. 37:632-640.

Neville, T. L., D. A. Redmer, P. P. Borowicz, J. J. Reed, M. A. Ward, M. L. Johnson, J. B. Taylor, S. A. Soto-Navarro, K. A. Vonnahme, L. P. Reynolds, and J. S. Caton. 2010. Maternal dietary restriction and selenium supply alters messenger ribonucleic acid expression of angiogenic factors in maternal intestine, mammary gland, and fetal jejunal tissues during late gestation in pregnant ewe lambs. J. Anim. Sci. 88:2692-2702.

Neville, T. L., M. A. Ward, J. J. Reed, S. A. Soto-Navarro, S. L. Julius, P. P. Borowicz, J. B. Taylor, D. A. Redmer, L. P. Reynolds, and J. S. Caton. 2008. Effects of level and source of dietary selenium on maternal and fetal body weight, visceral organ mass, cellularity estimates and jejunal vascularity in pregnant ewe lambs. J. Anim. Sci. 86:890-901.

NRC. 1985. Nutrient Requirements of Sheep. 6th ed. National Academy Press, Washington, DC.

Paglia, D. E., and W. N. Valentine. 1967. Studies on the quantitative and qualitative characterization of erythrocyte glutathione peroxidase. J. Lab. Clin. Med. 70:158-169.

Redmer, D. A., R. P. Aitken, J. S. Milne, L. P. Reynolds, and J. M. Wallace. 2005. Influence of maternal nutrition on messenger RNA expression of placental angiogenic factors and their receptors at mid gestation in adolescent sheep. Biol. Reprod. 72:1004-1009.

Reed, J. J., M. A. Ward, K. A. Vonnahme, T. L. Neville, S. L. Julius, P. P. Borowicz, J. B. Taylor, D. A. Redmer, A. T. Grazul-Bilska, L. P. Reynolds, and J. S. Caton. 2007. Effects of selenium supply and dietary restriction on maternal and fetal body weight, visceral organ mass, cellularity estimates, and jejunal vascularity in pregnant ewe lambs. J. Anim. Sci. 85:2721-2733.

Reynolds, L. P., J. D. Kirsch, K. C. Kraft, and D. A. Redmer. 1998 Time-course of the uterine response to estradiol-17 $\beta$ in ovariectomized ewes: Expression of angiogenic factors. Biol. Reprod. $59: 613-620$.

Swanson, T. J., C. J. Hammer, J. S. Luther, D. B. Carlson, J. B. Taylor, D. A. Redmer, T. L. Neville, J. J. Reed, L. P. Reynolds, J. S. Caton, and K. A. Vonnahme. 2008. Effects of gestational plane of nutrition and selenium supplementation on mammary development and colostrum quality in pregnant ewe lambs. J. Anim. Sci. $86: 2415-2423$. 
Vogel, C., A. Bauer, M. Wiesnet, K. T. Preissner, W. Schaper, H. H. Marti, and S. Fischer. 2007. Flt-1, but not Flk-1 mediates hyperpermeability through activation of the PI3-K/Akt pathway. J. Cell. Physiol. 212:236-243.

Vonnahme, K. A., D. A. Redmer, E. Borowczyk, J. J. Bilski, J. S. Luther, M. L. Johnson, L. P. Reynolds, and A. T. Grazul-Bilska. 2006. Vascular composition, apoptosis, and expression of angiogen- ic factors in the corpus luteum during prostaglandin $\mathrm{F}_{2 \alpha}$-induced regression in sheep. Reproduction 131:1115-1126.

Vonnahme, K. A., M. J. Zhu, P. P. Borowicz, T. W. Geary, B. W. Hess, L. P. Reynolds, J. S. Caton, W. J. Means, and S. P. Ford 2007. Effect of early gestational undernutrition on angiogenic factor expression and vascularity in the bovine placentome. J. Anim. Sci. 85:2464-2472. 